\title{
Dispute resolution methods in the construction industry sector in the Kingdom of Saudi Arabia
}

\author{
Saad Alshahrani ${ }^{1, \star}$ \\ ${ }^{1}$ School of the Built Environment, University of Salford, 4th Floor, Maxwell Building, M5 4WT
}

\begin{abstract}
The construction industry sector in the Kingdom of Saudi Arabia has undergone significant developments in the economics field, in terms of building tunnels, bridges, railways, airports, universities, etc. It is known that any project can involve disputes between the owner, consultant, and contractor of the project. Therefore, the researcher of this study investigated the methods of dispute resolution used in the economics sector in Saudi Arabia. These methods are negotiation and litigation. The researcher used mixed methods to collect the data. He interviewed 15 experts, academics, and arbitrators and then distributed a questionnaire to 327 experts, academics, and arbitrators. After that, the researcher analysed the gathered data by using both quantitative and qualitative methods. The researcher concluded that litigation is the method commonly used in the construction industry sector to solve disputes, and it is rare to use negotiation method. Also, the researcher found out that alternative dispute resolution methods are rarely used because the public work contract prevents the use of methods other than litigation.
\end{abstract}

\section{Introduction}

According to [1], there are three predominant categories of dispute resolution methods in the construction industry, (i) litigation, (ii) arbitration and (iii) alternative dispute resolution (ADR), a process which allows parties to come to a settlement based on their own negotiations, rather than a formal litigious procedure. These methods include negotiating, mediating and arbitrating. According to [2], the increasing cost of litigation has made quicker and less expensive methods of dispute resolution more attractive to parties. Expense not only include the compensation to be paid on settlement, but other financial losses sustained while conducting a construction dispute [3], which could be very costly for the losing party [4]. [5] point out that in order to improve the effectiveness of project organisations in general, it is vital to reduce such non-value-adding costs.

\subsection{Litigation}

Litigation can be basically described as the system of dispute resolution facilitated by the state judicial system. It is generally a complex and formal process, regulated by a substantial number of rules and procedural requirements that may vary based on the state or county of the judicature [6]. The

\footnotetext{
^e-mail: saad.888@hotmail.com
} 
parties will find themselves in need of lawyers, solicitors and counsel for assistance in the presentation of their arguments to the courts and the judiciary, for such professionals are generally only those with such rights of audience and expertise in navigating the rules and their compliance. The process and personnel are not renowned for their perceived value for money and time expenditure. The proceedings are open and public, inviting scrutiny and an audience of those members of the public and commercial competition who find interest in the particulars of the dispute [7]. The speed of resolution, due to the complexity of the proceedings and rules, is not conducive to the effective continuation and completion of time important construction projects; research by [8] in India revealed that, on average, it takes between five and fifteen years to reach an adequate resolution in court. A court trial is a considerably more formal process than ADR, slower process and guided by stringent rules of procedure and evidence [9].

\subsection{Alternative Dispute Resolution}

ADR can be defined as "any method by which conflicts and disputes are resolved privately and other than through litigation in the public courts" [10]. In its various adaptable forms, it is a way of solving disputes without going to trial, and indeed almost 90 per cent of potential court cases are resolved by ADR prior to trial [9]. A considered advantage for the parties is that ADR is a method of considering arguments in a significantly less formal manner than a court case, and less intimidating to the parties involved [9]. Disputes tend to be determined more quickly and at considerably less expense in money and time, whilst still being assessed by experienced professional adjudicators [9]. Where agreed by the parties, the process has potentially the same binding, considered effect as a court verdict, and indeed may be filed at court for enforcement as a final judgement [9]. ADR is evidently has advantages in time and cost savings in a more flexible conciliatory atmosphere [11].

\section{Dispute Resolution (Qualitative Method)}

\subsection{Litigation}

Litigation remains a common method in the resolving of disputes in both private and public sectors of Saudi construction enterprises according to respondents. Anecdotal opinion abounds from the research contributors. Interviewee A11, supported by the opinions of Ac1, A12 and A9, asserted "most of construction projects disputes in public and private sectors are solved by litigation. This is because the legal system in the country does not allow using any other methods to solve any disputes in public sector. This is possible in private sector. The reason is cultural awareness". A7 stated "all of the disputes in Saudi construction projects in private as well as in public sectors are resolved by means of litigation and that is a waste of time and money. Some cases last as long as five years and the cost of lawyer and expert reporting is high".

\subsubsection{Experts' Reports}

Expert reports dealing with particular elements of disputes form a significant part of litigation in Saudi Arabia to assist a judge in his decision-making on matters which are unlikely to be within his own expertise in the construction industry. Ac1 asserts that "in most of the disputes in Saudi construction projects, the judge will ask for assistance from the Consulting Engineering Office (CEO) and engineer experts". A7 confirms this is common practice in court based litigation, and "the expert is usually a representative of the CEO and Engineering Arbitration Centre in the SCE". Interviewee A13 adds: "the Engineering Arbitration Centre in SCE tries to keep in regular, timely communication with the 
Ministry of Justice to ensure that the forwarded report will be of the quality required, particularly because arbitrators and experts dealing with the opinions therein have high levels of experience and capability under the umbrella of specialised engineering project administration." A11 is however critical of some purported CEO expertise in the area of problem analysis in particular project problems due to lack of their own professional capabilities and conformity with the requirements of a professional body, He adds that the cost of experts' reports is less compared to those of the SCE, suggesting less experience and professionalism in their preparation.

\subsection{ADR}

In this section different methods of Alternative Dispute Resolution utilised in the Saudi construction projects are considered separately.

\subsubsection{Negotiation}

In Saudi construction project disputes, negotiation is used in both public and private sectors. A12 notes "that is free of charge and its duration may not exceed a month". It is however apparently rarely used to its full beneficial effect, according to E13. Interviewee A6 added that: "through my long experience, I have not come across negotiation as a means of resolving disputes in private and public sectors but litigation was mainly used as method of resolving disputes". Interviewees believed that resolving disputes by means of negotiation differs from other methods in that does not take long time and the cost is low compared with other methods; A4 adds "if the both sides of a dispute started using negotiation more often, they may no more be in need for other methods". E2 concurs: "negotiation is a developed method and it is based on knowledge and understanding of both parties of disputes. In my perspective, it should be considered as a preliminary method of resolution and it may take only a few hours and will not cost anything at all".

\subsubsection{Mediation}

Mediation is more broadly used in the private sector in Saudi construction projects rather than in public disputes in which the state or its representatives are involved. It is acknowledged by most respondents as the most effective method of solving disputes in the SCP. E15 states "mediation is a method of much flexibility and it is simple. In my experience, its duration is short and it does not exceed more than 3 months. It costs little. Sometimes it is as little as a tip. It is not used very much. There is no reason for not using it, unless the social culture is preventing that". Ac1 says "mediation is the best alternative disputes resolution, but regrettably arbitrators or experts who try to use mediation feel embarrassed. Since all parties anticipate in the mediation free of charge, this is a negative point for mediation in my point of view." It appears that what is preventing mediation to be used to its full advantage is the lack of utility in public contract projects. The advantages are evident from the anecdotal comments of research respondents. A6, for example, states "mediation is good in solving disputes in Saudi construction projects, and it is the best of all in my perspective, but it is being rarely used. It may take about a month to resolve problems and that is one of its best characteristics". A12 argues "at the moment we need some method other than litigation to solve disputes, such as mediation which is characterised with flexibility, less cost and most importantly, a shorter timescale. Mediation always takes less time". A4 agrees, but suggests it is less used than it should be because of perceptions that there is a "lack of arbitrators and experts' knowledge about this method and its benefits". In the context of Saudi Arabia, interviewee A3 adds "mediation is a good method and with flexibility but is hardly used and that is because of lack of support from Ministry of Justice for its use." 
The use of the Dispute Adjudication Board (DAB) as method of alternative dispute resolution is not currently used to its full potential in Saudi construction projects, although eight of the research participants believe it has many potential advantages in this arena. A12, an arbitrator, describes how it would operate; "based on the experiences I had in Saudi Arabia, where I was member of the board and I was involved in this method of handling disputes and from the outset of a project, the dispute arbitration board starts to play its role. The number of its panel members for the hearing of a dispute is uneven, to avoid stalemate. It helps avoid halting a project because all of the disputes will immediately be handled on the site." Interviewee Ac1 stresses speed and flexibility and perhaps the most important positive point of this method is its conduct on site and consequent awareness of dispute details; necessary documentation is also within the dispute arbitration board's reach. The Dispute Arbitration Board has a considerable impact in the quick resolution of problems, but is not currently used effectively in Saudi Arabia.

\subsubsection{Arbitration}

Arbitration is only used to any significant extent in private sector of Saudi construction projects. Interviewee A11 comments "arbitration is a method that is only used in private sector as the system applied by the government does not allow any other methods but litigation to be used for solving disputes in SCP. As a result, no one generally refers to arbitration to resolve a dispute unless they are semi-state companies or experienced companies or businessmen. Sometimes it is used to save reputation of the business involved in the dispute, a cultural issue to many prominent businessmen who value social status." Interviewee E5 admires the arbitration method and says: "arbitration is an effective method in solving disputes in SCP and is better than litigation. It is less expensive than litigation, and also it takes less time than litigation does. In most of the cases it will not take more than six months". Not all respondents were so effusive in their admiration.

E8 is more critical of arbitration; he complains of high cost to private business, potentially more so than litigation, the cost of which is largely borne by the state. As a relatively formal process compared to other methods of ADR it can be a lengthy process. E15 agrees; "arbitration is within the framework of official litigation and we prefer those alternatives with more flexibility which are far away from being officially imposed and highly expensive measures, which involve longer procedures for both sides of dispute". The time taken by the arbitration process is commented upon by A3; "time is considered as negative point of arbitration since it takes a long time to resolve a dispute in SCP. I should remind you that I took part in arbitration for a case that took three years and this is not shorter than the time litigation takes to resolve a construction project dispute." Interviewee A4 asserts that "one of characteristics of the arbitration method is that it is based on obligation with no executive power. After arbitration has concluded, litigation is still likely to be involved and, due to some prohibition in a country, for example, usury, the judge may reject what has been concluded during the arbitration process. Some domestic or international companies therefore pursue their case to the Gulf Arbitration Centre in Bahrain, or to the Paris Bureau, or Arbitration Centre in London".

Interviewee A9 casts doubt on the character of the arbitration process, asserting "arbitrators should be impartial and fair towards the disputes, but they tend to turn into a lawyer for advice, especially when three or five arbitrators are involved. This is why many companies avoid arbitration and lean towards lawyers since the duty of lawyer is clearly known and the financial expenses are clear from the outset, whereas there is little clarity about arbitrator's wages." On the broader issue of cost, interviewee E10 states: "Arbitration is a costly method, compared to others. It is not easy to take part in it due to the expenses which will be incurred". He adds that there can be a religious or faith element to adjudications, pointing out 'if someone lacks any legal or religious background, he will not be able to occupy a position as an arbitrator; he will only act as an expert and his duty will be limited 
to expertise reporting, without being allowed to do arbitrating, or take part in a dispute resolution. In my opinion, an expert engineer with long years of experience who has taken part in solving disputes has the ability to take part in any engineering disputes".

The arbitrator (A4) said: There is a live practical example to solve disputes resolution, in terms of construction project needs in Saudi Arabia. A contractor who possesses a big company issued some complaints to an owner. This project consisted of residential buildings with 450 residential units, worth 120 million Saudi Riyal (SAR). The duration of the project was 450 days and the amount claimed by the contractor was 30 million Saudi Riyal (SAR) from the owner. The causes of dispute were numerous and are listed as follows:

- First cause: The owner requested the contractor install extra exit doors for each unit, giving an average of 450 exit doors.

- Second cause: The owner requested the contractor to change the water heater, which was not specified in the original contract.

- Third cause: There was a difference in the real area of the buildings' basement as it was $120 \mathrm{~m} 2 \mathrm{in}$ whilst the design stipulated that it was $140 \mathrm{~m} 2$ in real.

- Fourth cause: The contractor asked the owner to extend the time duration for the project, because the owner and consultant delayed approving the materials to be used for the project, and so this impacted on the project timing.

- Fifth cause: The change of consultant during the project by the owner had an impact on the overall timing of the project.

- Sixth cause: A delay by the owner in the time take to provide the contractor with the locations, as there were three separate locations.

- Seventh cause: The differences on the level of the locations with what was specified in the design, as some of the locations were wasteland belonging to the municipality, and so therefore this required extra work from the contractor to level the ground properly.

In return, the owner had some claims from the contractor, and these were as follows: First claim: He requested for the implementation of a $10 \%$ penalty for delaying compensation based on the contract. Second claim: He requested the cost for transferring the remaining project for the rubbish left behind from the contractor, as the owner claims that he hired a subcontractor to accomplish the outstanding work.

Resolving these type of causes of dispute were accomplished through the arbitration method and the final verdict was as follows: These claims and disputes stopped the project for a whole year, and then the disputes were resolved through the arbitration method, which resulted in a ruling in favour of the contractor for the sum of nine millions Saudi riyals (SAR), while the ruling in favour of the owner was for 12 million Saudi riyals (SAR), and a fine for $10 \%$ of the contract value.

Figure 1 illustrates that litigation is a means of dispute resolution in Saudi construction projects in both the public and private sector it is the dominant method used by parties in disagreement, especially because most of the large construction projects in the KSA are government sponsored. Simple negotiating is used rarely in both sectors according to research respondents, and mediation used rarely in the private sector, arguably because common practice in dispute resolution is to turn to the traditional court litigation. Arbitration on domestic Saudi based contract disputes is not used in the public sector. Negotiation, mediation, and DAB have clear advantages in terms of speed of resolution and cost which prevent more than necessary disruption to the construction progress; the respondents tended to agree on the characteristics of cost effectiveness, flexibility and time. There was some discrepancy in responses on the time and cost issues of arbitration, with profoundly divergent opinions on expense 


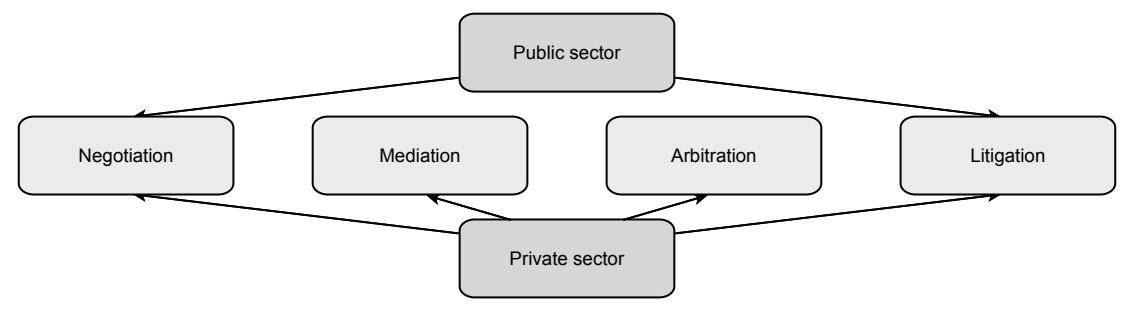

Figure 1. Method of Dispute resolution in Saudi Construction Project.

and length of proceedings reflecting respondents own experiences rather than, perhaps, theoretical perceptions.

\section{Dispute Resolution (Quantitive Method)}

In this question, a comparison on the approaches used for solving disputes for Saudi Construction Project in the public sector between participants from the public sector, private sector, and those participants who work in both private and public sectors was conducted. Resolutions in public sectors were through litigation and negotiation, according participants from public, private sectors and those who work in both sectors. The figure litigation was over $75 \%$, with that of negotiation in all sectors at less than $40 \%$.

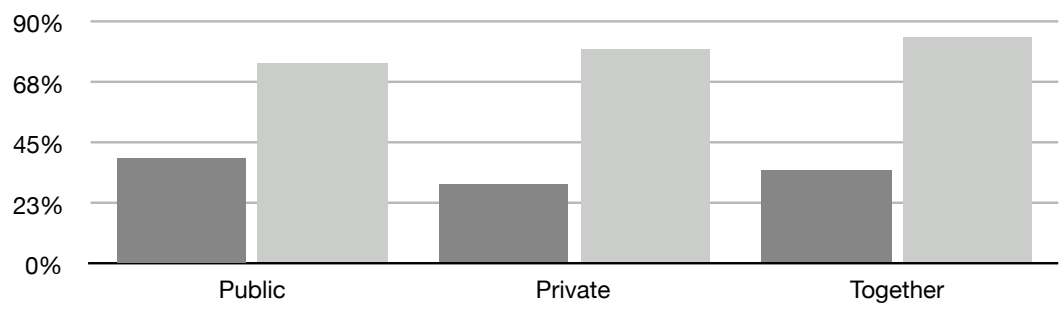

Figure 2. Comparing the percentage of use DRM and the participants who work in the public sector.

Figure 2 illustrates that the approach most commonly used in Saudi Construction Project in the public sector for dispute resolution was litigation which had the highest proportion of $85 \%$ according to the participants working in both private and public sectors. Participants working in the private sector considered disputes resolved by litigation to be less than that estimated by those working in both private and public sectors, which stood at $80 \%$. Participants from the private sector believed that the method of disputes resolution used for by litigation in the Saudi construction project in private sector was less, standing at $75 \%$. It is clear that disputes in Saudi construction project in the public sector were mainly resolved by means of negotiation according to participants working in both sectors, with the value standing at $40 \%$. According to participant working both sectors, the method of resolving disputes used in the Saudi construction project public sector was less than what was stated by participants from the public sector, with a figure of 35\%. According to participants from the private sector, disputes in the public Saudi Construction Project were resolved through negotiation, standing at 30\%. 
In this question, a comparison of the approaches used for DRM for Saudi Construction Project in the private sector between participants from the public sector, private sector, and those participants working in both the private and public sectors was conducted. It illustrates that disputes in the public sector were resolved through negotiation, litigation and mediation, according to participants from public, private sectors and those working in both sectors. DRM in the private sector use litigation according to participants working both private and public, having a high value at $86 \%$, while the DRM used in private sector for Saudi Construction Project is through arbitration according to participants, standing at $40 \%$ for participants working in both sectors.

Figure 3 illustrates that all of the participants, regardless of the sector, agreed that using litigation as means resolving disputes is the most common, at $86 \%$ for participants working in both sectors and it is higher when compared with the figures from those working in private sector and public sector. Participants from the public and private sectors were less than those working in both sectors. Their numbers were similar, at $67 \%$ and $66 \%$ respectively.

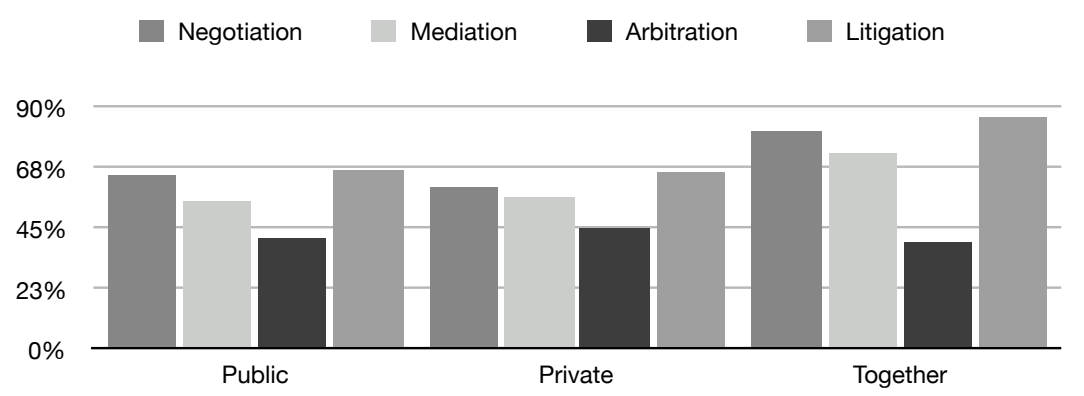

Figure 3. Comparing the percentage of use of DRM and the private sector worker.

Using DRM as a means of negotiation in private sector construction projects is applied mostly after litigation. The figure for this, according to participants who work in both sectors, was $81 \%$. For participants from private sector, it was $65 \%$, very close to the figure from participants working in both sectors. Those working in the private sector in DRM in Saudi Construction Project in the private sector used negotiation the least, with their figure standing at $60 \%$.

The used DRM in private sector Saudi Construction Project was next in third position after litigation and negotiation according to participants. Using mediation, according to those working in both sectors, was more common, at $73 \%$, while participants working in private sector had a different view regarding using mediation, considering it less than did those working in both sectors. The proportion for that was $57 \%$. We can see that, based on the opinions of participants from public sector, mediation has a lower figure, standing at $55 \%$.

The DRM used in the private Saudi Construction Project by means of arbitration was different to the previously used DRM. Previous DRM, according to participants working in both sectors, were higher. While using DRM as a means of arbitration for participants working in private sector was more common, at $45 \%$. Participants working in the public sector were less than those in private sector, at $41 \%$. At the end, we see that the participants working in both sectors together are fewer in number than participants from public sector and in their opinion, DRM by means of mediation was 40

In this question, the time taken to DRM in private sector was compared. As can be easily observed, the same duration was taken for both sectors in DRM. Considering that the four different approaches to DRM are litigation, negotiation, arbitration and mediation, the durations that each approach takes were as follows: 
Less than a month, 4-6 months, 7-12 months, 1-3 years and over 4 years. According to the participants, negotiation took less time for DRM resolution and the DRM would not be longer than one month, and the proportion for that is $72 \%$, while DRM by means of litigation took the most time, being over 4 years. The proportion of participants who pointed this out was $33 \%$.

Figure 4 illustrates that dispute resolution method in Saudi Construction Project by means of litigation took the most time. The participants who stated that DRM by means of litigation took 1 to 3 years constituted around $63 \%$ of the sample. While the figure for those who stated that it took over 4 years was $33 \%$.

Those who stated that dispute resolution method by means of litigation took about four to 12 months were small in number, not exceeding 1\%. Finally, the timing of over 4 months was not mentioned at all and no value was given to it.

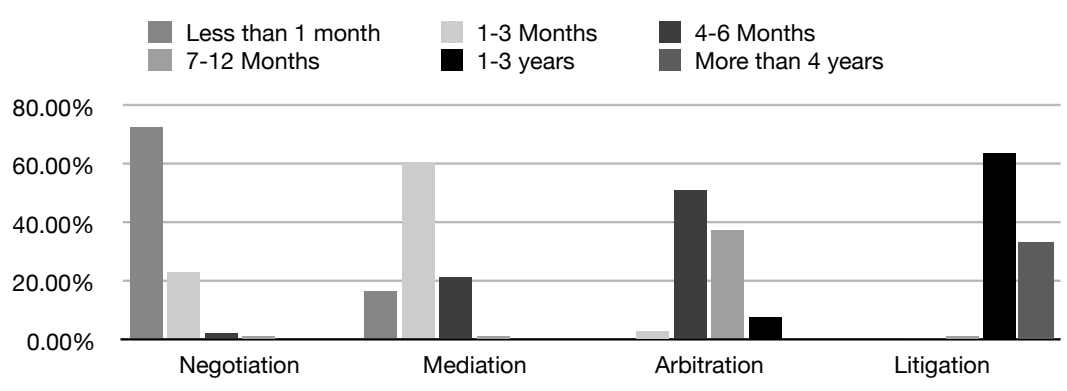

Figure 4. Percentage Time to Duration of Method of Dispute Resolution.

Participants who stated that the dispute resolution method by means of arbitration took four to 6 months were the largest group at $51 \%$, while those who stated that the dispute resolution method by means of mediation took seven to 12 months stood at $37 \%$ and came in second position. Next came those participants who said that the dispute resolution method by means of arbitration would take one to three years this group represented a small percentage, at $7 \%$. The smallest group of participants was those who stated that dispute resolution method by means of arbitration would take one to three months, at $3 \%$. Finally, no value was given by the participants with times of less than one month and over four years.

DRM by means of mediation according to participants who was stated that solving disputes by means of mediation takes 1 to 3 months was the most common, at $60 \%$. Those participants who believed that dispute resolution method through mediation took 4 to 6 months were in second position, with $16 \%$. It can be seen that the lowest figure given was very small and relates to those who stated that mediation took seven to 12 months, with a value of $1 \%$. Finally, times of over a year had no value.

Participants who said that dispute resolution method through negotiation took less than a month represented the largest group, at $72 \%$. Meanwhile, we can see that participants who stated that DRM by means of negotiation would take one to three years were in second in position, with a figure of $23 \%$. Those who state that dispute resolution method by means of negotiation will take 4 to 6 months, and its proportion was $2 \%$. But those who stated that the dispute resolution method by means of negotiation would take seven to 12 months were very few, compared to the time that was previously given. At the end, we see some timing that has no value, that being for periods of over one year.

In this question, the cost spent on dispute resolution in the SCE and the level of education of participants are compared. 
The DRM in the Saudi Construction Project are negotiation, mediation, arbitration and litigation. The levels of education of the participants are bachelor's degree, master's degree, $\mathrm{PhD}$ and higher diploma. As can be seen, dispute resolution using litigation has a high cost and, according to participants, the figure for this is over $47 \%$, being the highest of all. The figure given by those with higher diplomas was $100 \%$. Arbitration stood next to litigation in terms of cost. Using litigation for dispute resolution involved great cost and was over $45 \%$ for all of the participants. For those with $\mathrm{PhD}$ it was the highest, at $64 \%$. Using mediation as means of solving disputes came after arbitration in terms of cost. It was a low based on the participants' beliefs and was not over 33\%. For participants with bachelor's degrees it had the lowest cost, at $22 \%$.

Figure 5 illustrates that the method of dispute resolution by means of litigation takes the most expenses and according to participants with higher diplomas, had the highest figure compared to those $\mathrm{PhD}$ and master's degrees. The figure for holders of higher diplomas was $100 \%$. It can be seen that participants with higher diplomas believed that litigation had the highest expenses standing in second position, with a figure of $60 \%$. While with a figure of $65 \%$, given by those with $\mathrm{PhD}$ considering the cost of litigation in third position. At the end, participants with bachelor degrees stood lowest, with a figure of $47 \%$.

diplomas, master's degrees and bachelor's degrees had the highest cost and a figure of $64 \%$. It can be noticed that the participants with higher diplomas, in terms of cost of arbitration, stand in the second position with a figure of $60 \%$. Participants with master's degrees came in third with $54 \%$. Ultimately, the participants with master's degrees in terms of cost of arbitration represented the lowest figure, at $46 \%$.

Using mediation for dispute resolution was considered a low cost approach by all of the participants and the lowest prices are suggested by those with $\mathrm{PhD}$ with the value for the cost not exceeding $10 \%$. It can be observed that figure for the cost using mediation based on those with master's degrees did not exceed $12 \%$. Ultimately, the highest cost of dispute resolution through mediation was the opinion of those with higher diplomas who said that the figure for its cost was $22 \%$.

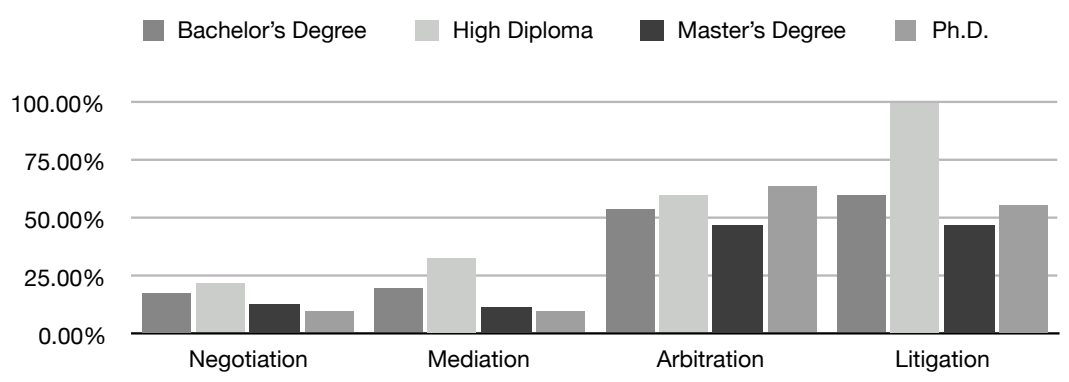

Figure 5. Comparing the percentage the cost of DRM used in the SCE and the level of Education.

Dispute resolution using negotiation, according to participants was very low cost and, in this case, the lowest cost refers to those with master's degrees, with the value not exceeding $20 \%$. Finally, according to participants with higher diplomas, the most costly method of dispute resolution was using negotiation with the figure for the cost of negotiation at 22 .

\section{Conclusion}

This article has considered, with the considerable assistance of experts in the field of Saudi construction projects, the status and value of ADR as an alternative to litigation in the resolution of construction 
industry disputes in the Kingdom. There are evident differences in the classification of the nature of disputes, and the factors, which govern the success of resolution. These are essential to ensure the efficacy of the projects and their effective completion. Disputes in Saudi construction projects have obvious impacts on time, cost and quality, which have to be properly managed to avoid costly delay. This article includes the qualitative and quantitative analysis. The aim is to achieve the objectives of research, whereby it is hoped the questionnaire will fill all the gaps in the literature. The questionnaire was distributed to arbitrators, experts and engineers in the public and private construction sector in KSA. With 327 responses being received from participants. . The questionnaire was designed and distributed using Survey Monkey, and the analysis of the questionnaire was performed using figures and tables.

Finally, the dispute resolution method in Saudi construction projects are considered in the context of (i) litigation, and (ii) alternative dispute resolution via negotiation, mediation, DAB and arbitration. The utility of such dispute resolution methods vary between the public sector, which involves the state or its agencies as a party to the contract and tend to seek resolution by negotiation or litigation, and the private sector, which makes use of the wider range of ADR processes.

\section{References}

[1] W. Hughes, R. Champion, J. Murdoch, Construction contracts: law and management (Routledge, 2015)

[2] P. Love, P. Davis, J. Ellis, S. On Cheung, Engineering, Construction and Architectural Management 17, 404 (2010)

[3] R.J. Gebken, G.E. Gibson, Journal of professional issues in engineering education and practice 132, 264 (2006)

[4] M. Li, S. Yu, Y. Zheng, K. Ren, W. Lou, IEEE transactions on parallel and distributed systems 24, 131 (2013)

[5] S. Cheung, C. Tam, I. Ndekugri, F. Harris, Construction Management \& Economics 18, 281 (2000)

[6] T.J. Kelleher Jr, J.M. Mastin, R.G. Robey, C. Smith, L. Hancock, Smith, Currie and Hancock's Common Sense Construction Law: A Practical Guide for the Construction Professional (John Wiley \& Sons, 2014)

[7] L. Greenhouse, Becoming Justice Blackmun: Harry Blackmun's Supreme Court Journey (Macmillan, 2007)

[8] K. Iyer, N. Chaphalkar, G. Joshi, International Journal of Project Management 26, 174 (2008)

[9] S. Harms, Traditional litigation versus alternative dispute resolution (in collection cases) (2011), http://www.jdsupra.com/legalnews/ traditional-litigation-versus-alternativ-97899/

[10] K.K. Kovach, Mediation: Principles and practice (Thomson West, St Paul, 2004)

[11] V. Chan, S.E. Tett, Pharmacoepidemiology and drug safety 15, 485 (2006) 